Sub Departamento de Neurología, Hospital Base de Valdivia. Valdivia, Chile. ${ }^{2}$ Subdepartamento de Medicina, Hospital Base de Valdivia. Valdivia, Chile.

${ }^{3}$ Laboratorio de Biología Molecular, Hospital Base de Valdivia. Valdivia, Chile. anterno Carrera de Medicina, Universidad Austral de Chile. Valdivia, Chile.

Trabajo no recibió financiamiento. Los autores declaran no tener conflictos de interés.

Recibido el 16 de agosto de 2018, aceptado el 19 de agosto de 2019.

Correspondencia a:

Dra. Claudia Reyes Subdepartamento de Neurología, Hospital Base de Valdivia Bueras 1003, Valdivia, Región de Los Ríos, Chile. reyesrojascivet@gmail.com

\section{Encefalitis por virus influenza $B$ en un paciente adulto. Reporte de caso}

\author{
CLAUDIA REYES ${ }^{1}$, SEBASTIÁN MIRANDA ${ }^{a}$, \\ ALBERTO FICA $^{2}$, MARITZA NAVARRETE ${ }^{3}$
}

\section{Encephalitis caused by type B influenza virus in an adult. Report of one case}

\begin{abstract}
Neurological manifestations associated with influenza virus infection include encephalitis, encephalopathy, acute necrotizing encephalitis, transverse myelitis, acute disseminated encephalomyelitis, mild encephalitis with reversible splenial syndrome (MERS), and Guillain Barré syndrome. We report a 16-year-old female who was admitted at our emergency department with seizures, confusion, nystagmus and motor clumsiness five days after an upper a respiratory tract infection. Influenza type B virus infection was confirmed by chain polymerase reaction analysis. The initial electroencephalogram demonstrated a pattern of global slowness without epileptic discharges. One week later, it showed a progression to slow-wave focal bilateral discharges at both temporal and occipital lobes. The patient had a favorable evolution and was discharged 19 days after admission with phenytoin to prevent seizures.
\end{abstract}

(Rev Med Chile 2019; 147: 922-927)

Key words: Electroencephalography; Encephalitis; Influenza, Human; Seizures.
L as complicaciones neurológicas asociadas a influenza son poco frecuentes y abarcan rré, encefapectro el sindrome de Guillain-Banecrotizante aguda (EAN), encefalitis con lesión esplénica reversible (MERS), mielitis transversa y encefalomielitis aguda diesmelinizante ${ }^{1-3}$. Estas complicaciones adquirieron mayor notoriedad en la pandemia de influenza A H1N1 el año 2009, sin embargo, la experiencia clínica latinoamericana con estas complicaciones es muy escasa, describiéndose sólo dos casos en Chile ${ }^{4,5} \mathrm{y}$ tres en el resto de Latinoamérica ${ }^{6,7}$; en los que destaca la presencia de compromiso de conciencia, convulsiones de inicio reciente asociados al virus de la influenza y todos ellos en población pediátrica. El objetivo de este trabajo es presentar un caso de encefalopatía asociada a influenza B y comentar sus características clínicas, electroencefalográficas, manejo y evolución. Como caso inusual puede alertar al equipo de salud sobre esta posibilidad.
Por escrito, la paciente dio su asentimiento y su padre el consentimiento para esta publicación.

\section{Caso clínico}

Paciente de sexo femenino de 16 años, sin antecedentes mórbidos, quien se presenta con un cuadro clínico tipo influenza en junio de 2017 con disfonía, congestión nasal, tos sin expectoración, emesis y fiebre hasta $39^{\circ} \mathrm{C}$. Inicialmente se le indica tratamiento sintomático, reconsulta al día 5 de evolución por persistencia de síntomas a lo que se agrega torpeza motora y dos episodios convulsivos de tipo generalizados. Posterior a la crisis, la paciente cursa con compromiso de conciencia que fluctúa entre episodios de agitación psicomotora, confusión y somnolencia sin evidencia de compromiso focal neurológico y signos meníngeos negativos.

En los exámenes de laboratorio los valores de 
la proteína $\mathrm{C}$ reactiva y leucocitos en sangre eran normales, test VIH negativo, con una tomografía computada cerebral que no mostraba hallazgos patológicos. El estudio del LCR mostró valores normales de proteínas, glucorraquia y glóbulos blancos según valores de referencia (Tabla 1) y el panel molecular múltiplex de una muestra de LCR descarta infección por citomegalovirus, herpes simplex 1-2, virus herpes 6 y 7 , virus de Epstein Barr, varicela-zoster, adenovirus, enterovirus y parvovirus B19. La resonancia nuclear magnética (RNM) cerebral no demostró hallazgos patológicos.

Ingresó a la Unidad de Pacientes Críticos con diagnóstico de encefalitis viral y se inicia empíricamente aciclovir, fenitoína y quetiapina, por la sospecha de influenza se inicia tratamiento con oseltamivir oral por 5 días, la que se confirma por medio de RCP multiplex de un hisopado nasofaríngeo resultando positivo para virus influenza $\mathrm{B}$ sin coinfección con otros virus.

Evoluciona desorientada, bradipsíquica, con nistagmo rotatorio a izquierda. Dentro del estudio se realiza electroencefalograma (EEG, Figura 1A) que informa ausencia de ritmos normales con una lentitud generalizada compatible con un patrón encefalopático sin actividad epileptiforme. En día 9 de evolución se repite punción lumbar que no muestra alteraciones patológicas ni presencia de VHS-1/2 por RCP. Un segundo EEG tomado una semana después (Figura 1B) revela reaparición de ondas normales acompañado de salvas de ondas lentas focales bilaterales en lóbulos temporales y occipitales.

Desde la tercera semana evoluciona favorablemente, sin signos de focalidad neurológica, ni síntomas respiratorios y se decide su alta el día 19 con fenitoína oral. En el primer control a las 3 semanas del alta refiere presentar episodios de irritibilidad y cefalea los que no estaban antes del cuadro, sin nuevos episodios convulsivos y con un EEG de seguimiento normal (Figura 1C).

\section{Discusión}

La encefalitis por virus influenza es muy infrecuente en la población adulta, con pocos casos descritos en la literatura mundial los que suelen estar relacionados a los brotes estacionales anua$\operatorname{les}^{8-12}$. La poca frecuencia de esta complicación
Tabla 1. Valores normales de referencia de líquido cefalorraquídeo (LCR)

\begin{tabular}{|ll|}
\hline Parámetro & LCR normal \\
\hline Aspecto & Incoloro, transparente (agua de roca) \\
Leucocitos & $0-5 / \mu \mathrm{l}$ \\
Eritrocitos & $0 / \mu \mathrm{l}$ \\
Proteínas & $15-45 \mathrm{mg} / \mathrm{dl}$ \\
\hline Glucosa & $60-70 \%$ glucosa plasmática \\
& $65 \mathrm{mg} / \mathrm{dl}$ \\
\hline
\end{tabular}

genera para el equipo de salud una dificultad diagnóstica y terapéutica. Las manifestaciones neurológicas secundarias al cuadro infeccioso por influenza son variadas, presentándonse dentro de los primeros días hasta una semana de iniciado los síntomas respiratorios. Se reconocen en la literatura desde cuadros encefalopáticos y encefalíticos leves ${ }^{13}$ hasta cuadros de alta mortalidad como la encefalopatía necrotizante aguda (ENA $)^{1}$. Al tener todos ellos la misma sintomatología inicial caracterizada por compromiso de conciencia en grado variable se hace necesario considerar el espectro de manifestaciones para poder reconocer las de mayor gravedad y peor pronóstico (Tabla 2).

La aproximación diagnóstica de estos cuadros incluye la presencia de una infección viral, acompañado de síntomas neurológicos y apoyado con estudio imagenológico y del LCR. Este último aparece alterado en $68 \%$ de los $\operatorname{casos}^{9}$ y se caracteriza por presentar discreta pleocitosis de predominio mononuclear, elevación leve de proteínas con glucosa normal los que sugieren una etiología viral. El LCR puede estar completamente normal en $32 \%$ de los pacientes. El estudio molecular se hace así indispensable en el diagnóstico diferencial especialmente al considerar que existen otras etiologías más frecuentes como enterovirus y herpes virus. En línea con lo reportado, no encontramos anomalías citoquímicas en 2 estudios consecutivos del LCR en nuestra paciente ni causas alternativas.

$\mathrm{Al}$ igual que el LCR, el estudio con neuroimagen puede resultar normal como en nuestra paciente. Sin embargo, en algunos casos se presentan alteraciones difusas de sustancia blanca supra e infratentorial en secuencias potenciadas en T2 y con restricción a la difusión ${ }^{8}$, edema cerebral en 


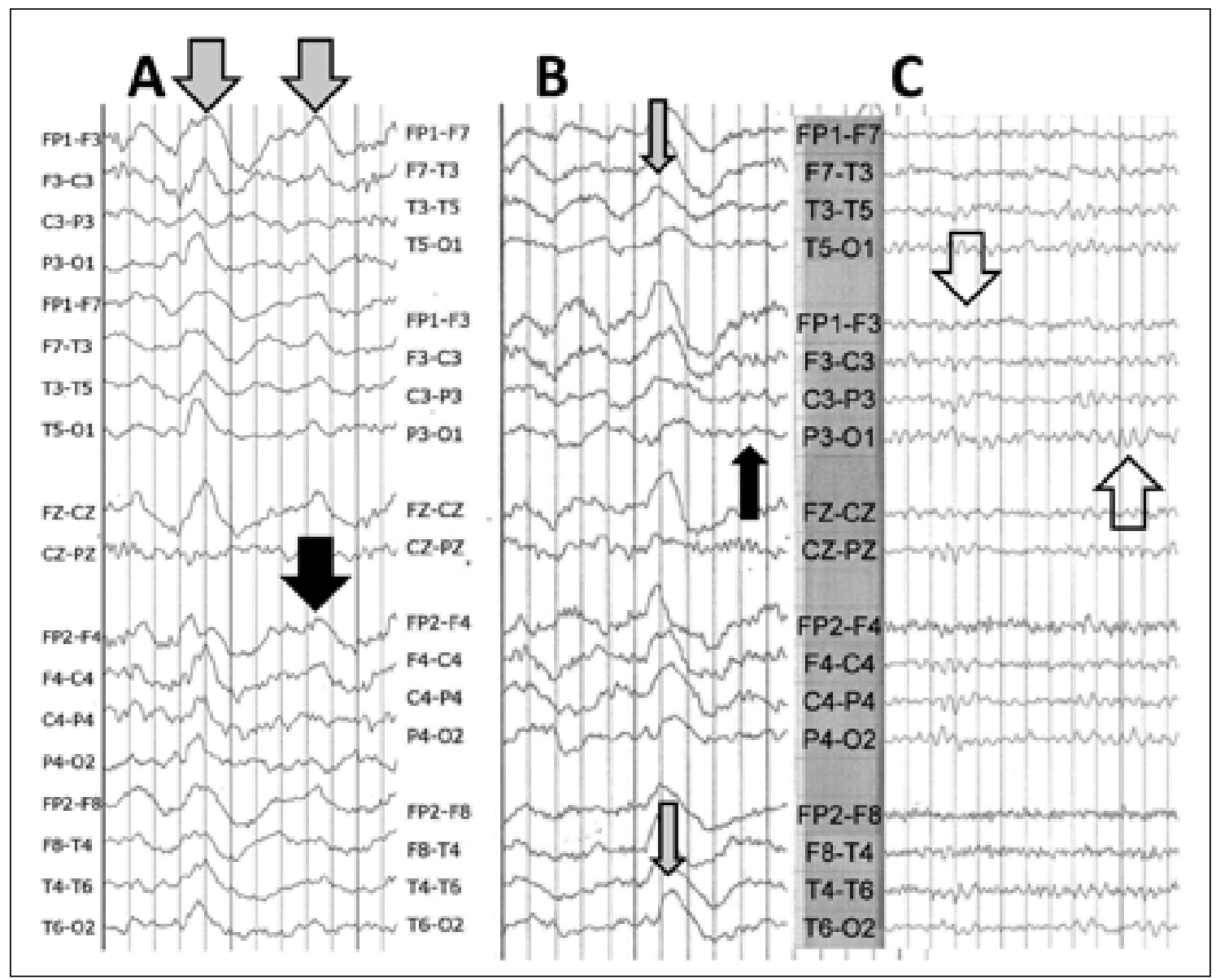

Figura 1. Un EEG normal, como el observado al momento de recuperación de la paciente (Figura 1C), se caracteriza por la presencia de ritmos alfa y beta de alta frecuencia (alfa 8-12 ciclos por segundo o Hz; beta $>13 \mathrm{~Hz}$, flechas blancas). Estos ritmos están ausentes en el primer trazado de la paciente (Figura 1A) y además han sido reemplazados por actividad lenta continua y generalizada de baja frecuencia de 5-7 ciclos por segundo denominadas ondas theta (flechas negras) acompañadas de otras ondas lentas de menor frecuencia aún (ondas delta; 1,5 Hz) con un patrón rítmico en posición frontal conocidas como FIRDA (Frontal Intermittent Rhythmic Delta Activity) (Flechas grises). En el EEG tomado a una semana de evolución reaparece el ritmo alfa (flecha delgada negra en Figura 1B) con salvas de ondas lentas de localización temporal y occipital (flecha delgada gris en Figura 1B). Los trazados presentados evidencian un patrón encefalopático difuso inicial dado por la lentitud generalizada (1A) que evoluciona hacia un compromiso focal dado por las salvas de ondas lentas (1B) y con recuperación completa de los ritmos de base (1C).

grado variable, siendo más evidentes este tipo de alteraciones en los casos de encefalitis necrotizante aguda (ENA) ${ }^{14}$. La literatura sugiere una relación entre mayores alteraciones imagenológicas con mortalidad y secuelas neurológicas ${ }^{8,14}$. El EEG por su parte no es específico y muestra en el 60\% de los casos una lentitud difusa de la actividad eléctrica cerebral lo que apoya el diagnóstico de cuadro encefalopático ${ }^{9,13,15}$, como se evidenció en nuestro caso y que además de ser evolutivos evidenciaron la recuperación completa del registro ${ }^{10}$. Se han descrito también, descargas epileptiformes periódicas lateralizadas ${ }^{16}$, lo que está históricamente asociado a encefalitis por herpes virus tipo 1, señalando lo inespecífico del EEG y la importancia del diagnóstico microbiológico.

La sospecha de una complicación a nivel de sistema nervioso asociada a infección por virus influenza comienza con la presentación de síntomas neurológicos, en un paciente con un 
Tabla 2. Cuadro comparativo entre diferentes complicaciones neurológicas del SNC asociadas al virus influenza

\begin{tabular}{|c|c|c|c|c|}
\hline Parámetro & $\begin{array}{l}\text { Síndrome de } \\
\text { Reye }\end{array}$ & $\begin{array}{l}\text { Encefalopatía / } \\
\text { encefalitis asociada } \\
\text { a influenza }\end{array}$ & $\begin{array}{l}\text { Encefalopatía } \\
\text { necrotizante aguda }\end{array}$ & $\begin{array}{l}\text { Encefalomielitis } \\
\text { aguda } \\
\text { desmielinizante }\end{array}$ \\
\hline Patogenia & $\begin{array}{l}\text { Encefalopatía no } \\
\text { inflamatoria asociada } \\
\text { a esteatohepatopatía }\end{array}$ & $\begin{array}{l}\text { Encefalopatía } \\
\text { inflamatoria }\end{array}$ & Encefalopatía inflamatoria & $\begin{array}{l}\text { Enfalomielitis inflamatoria } \\
\text { desmielinizante }\end{array}$ \\
\hline $\begin{array}{l}\text { Cuadro } \\
\text { clínico }\end{array}$ & $\begin{array}{l}\text { Alteración de } \\
\text { conciencia } \\
\text { rápidamente } \\
\text { progresiva }\end{array}$ & $\begin{array}{l}\text { Fiebre, } \\
\text { alteración de } \\
\text { conciencia, focalidad } \\
\text { neurológica }\end{array}$ & $\begin{array}{l}\text { Fiebre, alteración de } \\
\text { conciencia rápidamente } \\
\text { progresiva, coma }\end{array}$ & $\begin{array}{l}\text { Alteración de conciencia } \\
\text { con déficit neurológico } \\
\text { multifocal. Prodromo } \\
\text { de fiebre, irritabilidad y } \\
\text { somnolencia. Aparece } \\
\text { días después del cuadro } \\
\text { respiratorio }\end{array}$ \\
\hline Convulsiones & Presentes & Presentes & Presentes & Presentes \\
\hline LCR & LCR normal & $\begin{array}{l}\text { LCR puede ser normal, } \\
\text { leve pleocitosis, } \\
\text { discreta elevación de } \\
\text { monocitos }\end{array}$ & $\begin{array}{l}\text { LCR puede mostrar } \\
\text { pleocitosis con discreta } \\
\text { elevación de monocitos. }\end{array}$ & $\begin{array}{l}\text { LCR muestra } \\
\text { pleocitosis > a } 50 \mathrm{cl} / \\
\mathrm{mm}^{3} \text { con predominio } \\
\text { polimorfonuclear y } \\
\text { proteinas }>100 \mathrm{mg} / \mathrm{dl}\end{array}$ \\
\hline $\begin{array}{l}\text { RMN cere- } \\
\text { bral }\end{array}$ & $\begin{array}{l}\text { Puede mostrar } \\
\text { edema difuso } \\
\text { cerebral sin lesiones } \\
\text { focales }\end{array}$ & $\begin{array}{l}\text { Puede mostrar lesiones } \\
\text { talámicas bilaterales } \\
\text { con edema cortical } \\
\text { difuso }\end{array}$ & $\begin{array}{l}\text { Muestra lesiones } \\
\text { multifocales bilaterales } \\
\text { en el tálamo, tronco, } \\
\text { sustancia gris } \\
\text { periventricular y médula } \\
\text { asociado a edema } \\
\text { cerebral difuso }\end{array}$ & $\begin{array}{l}\text { Lesiones desmielinizantes } \\
\text { (sustancia blanca) cortico } \\
\text { subcorticales bilaterales y } \\
\text { medulares tumefactas y } \\
\text { con captación contraste } \\
\text { en } 30 \%\end{array}$ \\
\hline Manejo & $\begin{array}{l}\text { Soporte en } \\
\text { UCI, manejo de } \\
\text { edema cerebral, } \\
\text { anticonvulsivante, } \\
\text { antiviral }\end{array}$ & $\begin{array}{l}\text { Soporte en UCI, manejo } \\
\text { de edema cerebral, } \\
\text { anticonvulsivante, } \\
\text { antiviral }\end{array}$ & $\begin{array}{l}\text { Soporte en UCI, manejo } \\
\text { de edema cerebral, } \\
\text { anticonvulsivante, } \\
\text { antiviral, reportes de uso } \\
\text { de metilprednisolona, } \\
\text { inmunoglobulinas, } \\
\text { plasmaferesis, hipotermia }\end{array}$ & $\begin{array}{l}\text { Soporte en } \mathrm{UCl} \text {, } \\
\text { anticonvulsivante, } \\
\text { metilprednisolona, } \\
\text { inmunoglobulinas, } \\
\text { plasmaféresis }\end{array}$ \\
\hline Pronóstico & $\begin{array}{l}\text { Mortalidad } 40-50 \% \\
\text { Secuelas 100\% } \\
\text { sobrevivientes }\end{array}$ & $\begin{array}{l}\text { Mortalidad } 18-28 \% \\
\text { Secuelas en } 20 \% \text { de los } \\
\text { sobrevivientes }\end{array}$ & Mortalidad 30\% & Mortalidad 1-3\% \\
\hline
\end{tabular}

cuadro respiratorio alto concurrente o precedente. El diagnóstico etiológico se fundamenta en el hallazgo del virus influenza en aspirado o hisopado nasofaríngeo por inmunofluorescencia o métodos moleculares ${ }^{14}$. Alternativamente, el diagnóstico puede ser efectuado por métodos serológicos seriados con alza de títulos ${ }^{1}$. El estudio directo del virus influenza en el LCR sólo ocasionalmente ha sido positivo ${ }^{9}$ lo que pudiese estar explicado por una baja tasa de replicación viral o aclaramiento del virus al momento de toma de la muestra ${ }^{17}$.
La mortalidad descrita en casos de encefalitis por influenza es elevada $18-28,5 \%$ y puede además asociarse a secuelas neurológicas irreversibles en cerca de $20 \%{ }^{8.9}$. La mortalidad aumenta en pacientes de menor edad y en aquellos con anomalías en las imágenes ${ }^{1}$. Así, se reporta una recuperación sin secuelas en $78 \%$ de los pacientes con neuroimagen normal en contraposición a 50\% de pacientes con anomalías ${ }^{1}$. En casos de EAN, la mortalidad llega al 30\%, tal como ha sido descrito en Chile y en otras latitudes ${ }^{4,5,14}$.

Al ser una patología de curso impredecible, el 
manejo debe ser en unidades de pacientes críticos donde se entregue tratamiento de soporte adecuada para el manejo de posibles complicaciones. No queda claro en nuestro caso el beneficio del uso de oseltamivir, el que además se inició a los 7 días de evolución, otros reportes también describen su uso empírico ${ }^{8,9,12}$. La ausencia de comorbilidades crónicas y la edad de la paciente, no la hacían candidata a recibir la vacuna anual de la influenza, estrategia que tal vez podría haber impedido esta complicación.

Creemos que en este caso la sospecha de encefalitis por influenza tipo b está respaldada por la infección viral adecuadamente demostrada, por los síntomas neurológicos que incluyeron convulsiones, bradipsiquia, nistagmo, alteraciones electroencefalográficas y la exclusión apropiada de otras etiologías, la ausencia de lesiones en la resonancia magnética permite descartar la presencia de encefalomielitis aguda diseminada (ADEM) y de encefalopatía necrotizante aguda, dado que no hubo síntomas ni signos de compromiso hepático no es planteable un síndrome de Reye. Además presenta similitudes en el espectro de manifestaciones clínicas, el perfil epidemiológico y las alteraciones electroencefalográficas a los casos disponibles en la literatura, y refuerza el hecho de considerar el electroencefalograma como elemento importante de apoyo diagnóstico.

En conclusión, la Influenza tipo B es un virus con la capacidad de ocasionar un espectro de complicaciones neurológicas, según lo expuesto en la literatura mucho más frecuentes en población infantil, lo que puede hacer pensar que en el mecanismo fisiopatológico puede estar involucrado la madurez del sistema nervioso, incluida la barrera hematoencefalica, que permitiría a temprana edad la migración de la reacción inflamatoria desencadenada por el patógeno a estructuras encefálicas. Estas complicaciones deben ser sospechadas en pacientes que cursan con convulsiones o compromiso de conciencia durante un cuadro respiratorio viral. Aunque pueden no asociarse a alteraciones del LCR y rara vez a alteraciones en neuroimágenes, tienen una mortalidad significativa, especialmente en casos de encefalitis aguda necrotizante y pueden dejar secuelas. El diagnóstico se estable por la exclusión de otras causas y la confirmación de influenza por diferentes técnicas. Destacamos que el registro EEG, aunque inespecífico, puede confirmar un compromiso encefalopático evolutivo. El manejo considera una terapia de soporte, incluyendo el manejo de las convulsiones sin claridad sobre el beneficio de usar oseltamivir.

\section{Referencias}

1. Studahl M. Influenza virus and CNS manifestations. J Clin Virol 2003; 28 (3): 225-32.

2. Pohl D, Alper G, Van Haren K, Kornberg AJ, Lucchinetti CF, Tenembaum S, et al. Acute disseminated encephalomyelitis. Updates on an inflammatory CNS syndromes. Neurology 2016; 87 (9 Suppl 2): S38-45.

3. Vanderschueren G, Schotsmans K, Maréchal E, Crols R. Mild encephalitis with reversible splenial (MERS) lesion syndrome due to influenza B Virus. Pract Neurol 2018; $0: 1-2$.

4. Bustos R, Andrade F. Encefalopatía aguda y muerte encefálica en un niño con influenza A (H1N1) 2009 durante la primera ola pandémica en Concepción, Chile. Rev Chilena Infectol 2010; 27 (5): 413-6.

5. Zubieta M, Ferrés M, Bidart T. Importancia de las imágenes y el diágnostico etiológico en el paciente inmunocomprometido con afección del sistema nervioso central. Segunda parte. Rev Chilena Infectol 2011; 28 (4): 359-62.

6. Moreno N, Bayard V, Quiros E, Alonso T. Manifestaciones neuropsiquiátricas como expresión de infección por virus de influenza en Panamá. MEDICINA (Buenos Aires) 2009; 69 (1/): 121-6.

7. Valdivia-Tapia MC, Carreazo NY. Encefalopatía no fatal por influenza AH1N1 en paciente pediátrico en Perú. Rev Peru Med Exp Salud Publica 2016; 33 (3): 585-7.

8. Popescu C, Florescu S, Lupulescu E, Zaharia M, Tardei G, Lazar M, et al. Neurologic complications of influenza $B$ virus infection in adults. Romania. Emerg Infect Dis 2017; 23 (4): 574-81.

9. Mejier W, Linn F, Wensing AM, Leavis HL, van Riel D, Geurtsvan Kessel $\mathrm{CH}$, et al. Acute influenza virus-associated encephalitis and encephalopathy in adults: a challenging diagnosis. JMM Case Reports 2016; 3 (6): e005076.

10. Shimamoto M, Okada S, Terashima T. Encephalopathy associated with influenza B in a healthy young man. Intern Med 2017; 56 (14): 1925-9.

11. Ruisanchez-Nieva A, Martínez-Arroyo A, Gómez-Beldarrain M, Bocos Portillo J, García-Monco JC. Influenza-associated seizures in healthy adults. Epilepsy Behav Case Rep 2017; 8: 12-3.

12. Piet E, Tattevin P, Mailles A, Stahl JP. Influenza B me- 
ningoencephalitis in France. Med Mal Infect 2017; 47 (6): 435-6.

13. Toovey S. Influenza-associated central nervous system dysfunction: a literature review. Travel Med Infect Dis 2008; 6 (3): 114-24.

14. Mariotti P, Iorio R, Frisullo, Plantone D, Colantonio R, Tartaglione $\mathrm{T}$, et al. Acute necrotizing encephalopathy during novel influenza A (H1N1) virus infection. Ann Neurol 2010; 68 (1): 111-4.

15. Fuchigami T, Imai Y, Hasegawa M, Ishii W, Endo A,
Arakawa C, et al. Acute Encephalopaty with pandemic (H1N1) 2009 virus infection. Pediatr Emer Care 2012; 28 (10): 998-1002.

16. Kurita A, Furushima H, Yamada H, Inoue K. Periodic lateralized epileptiform discharges in influenza B-associated encefalophaty. Intern Med 2001; 40 (8): 813-6.

17. Wang G, Li R, Jiang Z, Gu L, Chen Y, Dai J, et al. Influenza virus induces inflammatory response in mouse primary cortical neurons with limited viral replication. Biomed Res Int 2016; 2016: 8076989. 